\title{
Building on shifting sands: The challenges of meeting the learning needs of adults in a rapidly changing world
}

\author{
Stephen Roche ${ }^{1}$
}

Published online: 25 May 2016

(C) Springer Science+Business Media Dordrecht and UNESCO Institute for Lifelong Learning 2016

The American adult educator Malcolm Knowles memorably wrote that "Pedagogy [has become] a millstone around education's neck" (Knowles 1973, p. 42). He noted that the idea and practice of pedagogy was developed in the monasteries of medieval Europe, with the principal aim of turning young novices into skilled and obedient servants of the Church, rather than free and creative thinkers. He identified in this approach a crucial break with the educational paradigm of the ancient world, where the emphasis lay on asking the right questions rather than giving the right answers, and whose great teachers (including Confucius, Jesus, Aristotle and Cicero) "were chiefly educators of adults, not children" (ibid., p. 42). Modern educators, he believed, were still burdened by monastic norms. In an attempt to cast off the cowl of pedagogy, Knowles helped to popularise the term "andragogy" as an alternative to the child-centred (and heavily loaded) "pedagogy".

Yet, more than 40 years after he wrote the above words, we are still awaiting the great revival of adult education. UNESCO's upcoming 3rd Global Report on Adult Learning and Education states that most countries still devote less than 2 per cent of their education budgets to adult education (UIL 2016). This is the current situation despite the fact that rapid social and technological changes have surely dispensed with the notion that the knowledge and skills acquired in childhood and youth will suffice for an entire working life. Some of the blame for such short-sightedness may lie with the current obsession, born in the wealthier nations and rapidly spreading to all, with assessment in schools, a trend which has helped to maintain the focus of education on children and dramatically shifted it from learning to achievement. The first five papers of this issue remind us of the crucial role adult education plays in the development of genuine learning societies. The final paper is, arguably, also

Stephen Roche

s.roche@unesco.org

1 UNESCO Institute for Lifelong Learning, Hamburg, Germany 
concerned with this topic, as it traces the effects of a non-formal learning scenario on groups of teenage students and their teachers.

Sixteen years into the new century, we have grown used to hearing politicians, business leaders and others issue warnings of the need to equip ourselves and our children with the skills required for the 21 st century. In fact, like the warnings about climate change, there is a risk that these have become dulled by repetition and the vague sense of helplessness with which they are often received. In her article entitled "Training 21st-century workers: Facts, fiction and memory illusions" Helen Abadzi explores what lies behind, within and beyond that warning, and she adds to it a new warning; not to ignore the basics in the rush to develop complex skills. She begins by unpacking the term " 21 st-century skills", the increasingly complex skill set that citizens require in order to survive and thrive in the global economy. Despite the involvement of multiple new actors and stakeholders in education and training, she contends that governments continue to bear the greatest responsibility for providing relevant education and training. But Abadzi's main point is that " $[\mathrm{t}] \mathrm{he}$ learning readiness of the well-to-do is transforming educational policies worldwide". She points out that international development agencies and donors often advise governments of developing countries to de-emphasise basic knowledge and skills and focus instead on complex cognition and systemic improvements. However, this advice rests on the biases of those proffering it; as a rule, they are highly educated people who may have forgotten quite how many stages it took to build their own current skill set. Effective training requires practice, feedback and rearrangement, because complex skills are built by combining and automatising shorter chains of thoughts or behaviours. This is referred to by neuroscientists as the development of "implicit memory". To provide complex skills for all, curricula should therefore first ensure detailed instruction and practice of basic components which can then be strung together and applied to new tasks. Curricula must also take into account the fundamental differences in the ways adults acquire new skills and knowledge, compared to children, due to changes in brain plasticity over time (Knowland and Thomas 2014).

Low basic skills levels among adults represent a complex policy problem with neither straightforward causes nor easy solutions, and successful interventions are still relatively rare. Tackling serious literacy and numeracy weaknesses among adults is challenging, partly because the task itself is difficult, and partly because even if accomplished successfully, the returns on investment (of expertise, time and money) are uncertain. The Survey of Adult Skills, an international investigation conducted in 22 member and two partner countries of the Organisation for Economic Co-operation and Development (OECD) as part of the Programme for the International Assessment of Adult Competencies (PIAAC), revealed that a considerable number of adults in the world's wealthiest countries possess only limited literacy and numeracy skills. Most governments now recognise that the maintenance of their national prosperity will depend on boosting the skills of these adults. In her article entitled "How to motivate adults with low literacy and numeracy skills to engage and persist in learning: A literature review of policy interventions", Hendrickje Catriona Windisch examines current evidence on policy interventions to pinpoint what has so far proven to motivate adults to join and persist 
in basic literacy and numeracy learning. The author identifies three approaches which seem promising in helping to address individual learners' needs: adapting instruction to learners' needs by means of regular assessment (formative assessment); complementary e-learning (blended learning); and contextualisation of basic skills provision both at work and at home (workplace learning and family literacy). The central challenge, she remarks, is putting the evidence to work.

Another important but often neglected component of adult education are the pathways back into the formal education system for adults who may have dropped out or underachieved at an earlier stage. Not incidentally, those countries with the longest and strongest traditions of adult education - such as the nations of Scandinavia - have often been the first to develop effective "second-chance" routes (Orr and Hovdhaugen 2014). However, the value of offering multiple routes into third-level education has now been widely understood and embraced, and forms a key component of lifelong learning policies in many countries. In our third article, entitled "Second-chance university admission, the theory of planned behaviour and student achievement", authors Yabit Alas, Muhammad Anshari, Norakmarul Ihsan Sabtu and Norazmah Yunus examine the UniBridge programme of Universiti Brunei Darussalam (UBD) through the lens of the theory of planned behaviour, which attempts to explain the factors which influence behaviour. They compare the academic performance of students entering the university via direct intake with those who enter following the intensive one-semester bridging course, designed to prepare them for undergraduate-level study. Using a mixed-methods approach, the authors subjected student performance data of both direct intake and bridgeprogramme undergraduates to statistical analyses, carried out interviews and then identified individual attitudes and social pressures which form an intention to prepare for entry examinations. They show that the two groups were competitive in terms of undergraduate academic achievement, thus proving the second-chance programme to be effective in enabling students with poor school-leaving results to experience academic confidence at university level. On the strength of these findings, the authors conclude their paper with recommendations for tertiary institutions to support lifelong learning initiatives through the use of multiple channels of entry.

Policy discussions on adult education invariably throw up the topic of "professionalisation" of adult educators. At first glance, the use of this term would seem to suggest that adult educators do not yet belong to a profession, or alternatively that they lack "professionalism" in how they work. While the intentions of those who use the term are probably more benign than this, signifying rather a formalised and standardised approach to how adult educators are trained, the uncritical use of this term implies an ambiguity about the role and status of adult educators that does not apply to other educators. It prompts us to interrogate the meaning of the term "profession". If (as the authors of our next paper suggest) a profession may be defined as "a group of people who work within a common practice with a theoretical knowledge base and an ethical code for which education and training are needed", most adult educators fit the bill. However, the authors also note that, in common usage, "it is fundamental to the notion of a profession that it is 
controlled by its members". By this criterion, we might certainly doubt the "professionalism" of many adult educators.

Lesley Doyle, Regina Egetenmeyer, Chetan Singai and Uma Devi begin their paper, entitled "Professionalisation as development and as regulation: Adult education in Germany, the United Kingdom and India", with an outline of current policies regarding the professionalisation and standardisation of adult education. Their aim is to identify how the terms "professionalisation" and "professionalism" are applied, to assess where occupational control is situated in the three countries studied (all with long and diverse traditions of adult education), and to discover what adult educators can do to regain control over their own profession. To assist their analysis, they apply American sociologist Eliot Freidson's "third logic" models, with his juxtaposition of "professions", "the market" and "bureaucracy", to examine the organisations and policies which control the standardisation processes in the three countries. They seek along the way to disentangle what they see as contradictory uses of the term "professionalisation", and conclude with an appeal for adult educators "to consider their position in professional terms in order to regulate and control their own standards", both in their own interests and in the interests of those they educate.

Our fifth paper, a research note entitled “Adult educators' core competences" by Bjarne Wahlgren, considers the knowledge, skills and mental ability required by educators working in the four principal domains of adult education - vocational education, corporate education, social and moral education, and cultural and arts education. The author drew his findings from three surveys of experts in Europe and North America, and from a comparative study of adult educator training curricula in Europe. The aim of this note is to identify commonalities and thereby distil the core competences required by adult educators, organised into four thematic subcategories: communicating subject knowledge; considering students' prior learning; supporting a learning environment; and reflection on their own performance. In his analysis, the author concludes that it is just as important to teach students to apply what they have learned as it is to teach them to learn. He notes that this ability to train adult learners in a way which enables them to apply and use what they have learned in practice (thus performing knowledge transfer) still appears to be undervalued.

The essence of lifelong learning is the faculty, acquired as early as possible, to treat every life event and situation as a learning opportunity. Schools have frequently been criticised for inhibiting rather than fostering that faculty; in the past through authoritarian didactics; more recently through crowded curricula and a focus on testing (Muskin 2015). Field trips therefore provide a vital opportunity for both students and teachers to escape the crucible of the classroom and enjoy a more personal and expansive learning experience. Typically, rural students are disadvantaged in this regard, as rural public schools often lack the resources or must contend with excessive obstacles in terms of distance to undertake cultural and educational field trips. Our final paper of this issue, entitled "The impact of a museum travelling exhibition on middle school teachers and students from rural, low-income homes", describes how students from five middle schools in the United States (usually encompassing grades 6 to 8 and attended by children aged 11 to 14) 
responded to a travelling museum exhibition hosted at a non-museum site. The authors, James Badger and Richard J. W. Harker, explore the impact of the exhibition on students from disadvantaged rural backgrounds, discussing how it helped them to engage with themes such as freedom of expression, democracy, citizenship and Holocaust education. The results show that, by connecting curricular content with real-life situations, field trips such as the one studied have the potential to change not only students' understanding of the curriculum, but also their teachers' estimation of their abilities.

\section{References}

Knowland, V. C. P., \& Thomas, M. S. C. (2014). Educating the adult brain: How the neuroscience of learning can inform educational policy. International Review of Education, 60(1), 99-122.

Knowles, M. (1973). The adult learner: A neglected species. Houston: Gulf Publishing Co.

Muskin, J. A. (2015). Student learning assessment and the curriculum: Issues and implications for policy, design and implementation. Geneva: UNESCO International Bureau of Education.

Orr, D., \& Hovdhaugen, E. (2014). "Second chance" routes into higher education: Sweden, Norway and Germany compared. International Journal of Lifelong Education, 33(1), 45-61.

UIL (UNESCO Institute for Lifelong Learning), (2016). 3rd global report on adult learning and education. Hamburg: UIL. (in preparation). 